\title{
Stochastic Capital Depreciation and the Comovement of Hours and Productivity
}

July 2002

\author{
Michael J. Dueker $\ddagger$ \\ Andreas M. Fischer† \\ and \\ Robert D. Dittmar $\ddagger$
}

\begin{abstract}
In this article, we demonstrate that a small degree of stochastic variation in the depreciation rate of capital can greatly reduce the comovement between hours worked and labor productivity in a neoclassical growth model. The depreciation rate is modeled as a Markov process, as opposed to a linear autoregressive process, to place a strict upper bound and to ensure that variation and not the level of the rate is driving the result. Markov switching implies nonlinear decision rules in the dynamic stochastic general equilibrium model (DSGE). Our contribution to solving DSGE models with Markov switching is to apply Judd's (1998) projection method to capture the nonlinearity in the decision rules. This approach allows for nonlinear decision rules in a richer set of models with many more state variables than can be solved with grid-based approximations. The results presented here suggest that Markov switching parameters offer a powerful extension to DSGE models.
\end{abstract}

Keywords: Markov Switching, Nonlinear Decision Rules, Hours-Productivity Corr. JEL Classification Number: C63, E22, and E32

† Federal Reserve Bank of St. Louis, P.O. Box 442, St. Louis, MO 63166, USA

michael.j.dueker@stls.frb.org, robert.dittmar@stls.frb.org,

† Swiss National Bank and CEPR, Postfach, 8022 Zurich, Switzerland, fischer.andreas@snb.ch 


\section{Introduction}

Numerous dynamic stochastic general equilibrium (DSGE) macroeconomic models now allow for variation in the depreciation rate of capital. One approach treats the depreciation rate to be an endogenous variable such that the choice to use capital intensively or to spend little on maintenance and repair results in high depreciation [Greenwood, Hercowitz and Huffman (1988); Burnside, Eichenbaum and Rebelo (1996); King and Rebelo (2000) for the former; McGrattan and Schmitz (1999), Collard and Kollintzas (2000) and Licandro and Puch (2000) for the latter]. Procyclical variation in capital utilization amplifies the effect of a technology shock on output. Thus, the variance of technology shocks can be lower in a model with variable capital utilization, with fewer implied occurrences of technical regress. When the depreciation rate is a function of maintenance and repair, the assumption is that each unit of capital is matched with labor input that is geared toward either production or capital maintenance and repair. In this case, technology shocks have an income and a substitution effect on the rate of depreciation. The substitution effect is positive because a positive productivity shock causes goods production to be relatively more efficient than maintenance. The income effect is negative because a positive productivity shock reduces the labor input needed to produce a given quantity of consumer goods, freeing labor for alternative activities including maintenance. In both of these scenarios, variation in the depreciation rate is a means and not an end. Endogenous depreciation equates margins at less than full capital utilization or introduces a role for large, countercyclical expenditures 
on maintenance and repair. In this way, endogenous depreciation serves to amplify and augments the persistence of the effects of technology shocks on output. But, fully endogenous depreciation only amplifies technology shocks and does not allow for random changes in the depreciation rate as an independent source of economic fluctuations.

Stochastic depreciation, on the other hand, allows depreciation shocks to serve as an additional driving force behind macroeconomic fluctuations, along with technology shocks. In this article, we concentrate on illustrating how stochastic depreciation can help generalequilibrium models match labor-market data. Our results suggest that it might be fruitful in business cycle research if stochastic shocks to the depreciation rate were added to models in which the expected rate of depreciation varied across time as a function of choice variablesa melding of the endogenous and exogenous approaches to depreciation. Nevertheless, even in the exogenous strand, one motivation for exogenous variation in the depreciation rate is that it serves as a shorthand approach to complicated endogenous scrappage decisions that are hard to build into a DSGE model. For example, a high rate of obsolescence of energy-intensive capital in the face of the 1970s oil price shocks might very well have been an endogenous response to a particular type of shock. Rather than add a lot of structure, a modeler might choose to treat such an episode as a surprise and temporary exogenous increase in the depreciation rate. Ambler and Paquet (1994) introduce stochastic depreciation as a persistent autoregressive process much like technology. Such depreciation shocks help the model match an important feature of U.S. labor markets that elude real business cycle (RBC) models: hours and productivity have only a small positive correlation, 
rather than the large positive correlation implied by the standard RBC model that relies solely on technology shocks.

We argue, however, that depreciation, unlike technology, is better modeled as a Markov process than an autoregressive process. The reason why Ambler and Paquet's (1994) autoregressive depreciation rate leads to a low hours-productivity correlation is somewhat ambiguous. A standard RBC model with a constant rate of depreciation can imply a low hours-productivity correlation if the depreciation rate is sufficiently high, as shown in Figure 1. Nevertheless, a quarterly rate of depreciation above 3 percent is generally considered implausibly high, so the standard RBC model cannot generate a low positive correlation between hours and productivity at empirically plausible parameter values. Ambler and Paquet's (1994) autoregressive process generates annual depreciation rates that fluctuate between roughly 4 and 14 percent. Thus, especially in light of Figure 1, Ambler and Paquet's autoregressive process does not firmly establish that stochastic fluctuations limited to low, empirically plausible rates of depreciation can account for a low hours-productivity correlation. An autoregressive process that is persistent also allows high rates of depreciation in simulations.

This article seeks to demonstrate that stochastic fluctuation of the depreciation rate within a narrow band at low and moderate levels is by itself able to generate a low hoursproductivity correlation, without the occurrence of high rates of depreciation. A Markov switching process is a natural way to achieve this combination of persitent fluctations within a narrow band. In this way, we reinforce Ambler and Paquet's point that stochastic depre- 
ciation induces a substantial reduction in the comovement of hours and labor productivity. The intuition is that a random increase in the depreciation rate causes hours worked and labor productivity to respond in opposite directions. When the depreciation rate rises, the capital-output ratio begins to fall, so labor hours are substituted for capital. Consequently, hours and labor productivity move in opposite directions. This source of negative correlation between hours and labor productivity can counteract the positive correlation implied by technology shocks to result in a low correlation between hours and productivity that matches the data.

To limit the range of fluctuation and the highest level of the depreciation rate, we model stochastic depreciation rates as the outcome of a two-state Markov switching process. Provided that the high depreciation state lies below the region where the level of the depreciation rate affects the hours-productivity correlation, we can be sure that any effect of stochastic depreciation on the hours-productivity correlation is coming from random changes in the depreciation rate, as opposed to realizations of a very high depreciation rate. Our results show that the high and low depreciation states do not have to be very far apart to generate low hours-productivity correlations at empirically plausible rates of depreciation.

This article also makes a useful contribution to the calculation of decision rules in the presence of Markov switching parameters. The approach followed by Gong (1995) to Markov switching was to calculate linear decision rules for each Markov state and then weight the rules by their probabilities. Andolfatto and Gomme (2001) introduce a Markov 
switching money growth rate and use a grid-based approximation to the nonlinear decision rule functions. As we discuss in Section 4, however, the grid-based approach can only be applied to relatively simple models with a very small number of state variables - three or less. Instead, we apply Judd's (1998) projection method of polynomial approximations to the nonlinear decision rules. The projection remains feasible for DSGE models with ten state variables or more. Without such methods, research involving Markov-switching parameters or other forms of nonlinear decision rules would be very limited in terms of dimensionality.

The article is organized as follows. Section 2 motivates our use of a Markov switching process for a time-varying depreciation rate. Various uncertainties concerning the persistence of depreciation are highlighted. Section 3 presents the baseline RBC model. The same section discusses calibration strategy. The solution procedure with nonlinear decision rules is outlined in Section 4. Section 5 presents the main results in the form of sensitivity analysis and impulse responses. Section 6 concludes.

\section{Difficulties in Calibrating Time-Varying Depreciation}

Empirical evidence on time-varying depreciation rates is scant for the U.S. economy. The accounting methods used for the construction of national accounts data typically assume constant depreciation rates. Hence, evidence on time-varying depreciation often comes from sectoral data that are not necessarily representative of the economy as a whole. 
In one of the few empirical studies on estimating time-varying depreciation rates, Abadir and Talmain (2001) use annual observations on real net investment and on real gross investment to calculate the macroeconomic depreciation rate from their implied capital stock measure. ${ }^{1}$ They find that depreciation rates differ substantially across countries for the period 1970 to 1996 . The estimates for the United States suggest the following characteristics: annual depreciation rates exhibit strong persistence; they fluctuate in a relatively narrow (trendless) band and they do not appear to be strongly procyclical. This suggests that capital is often destroyed or scrapped through factors other than intense capital utilization. Innovations that lead to obsolescence and scrappage is not always procyclical. In the service sector, which is heavily reliant on computers, the technology cycle of microprocessors - popularly known as Moore's law — is independent of the business cycle. Capital is also destroyed through natural disasters and rendered obsolete by large, unexpected relative price changes.

Our strategy for modeling time-varying depreciation is to assume that depreciation is driven by a Markov process that puts strict bounds on the lower and upper ranges of the depreciation rate, as the empirical study of Abadir and Talmain (2001) suggests. ${ }^{2}$ We

\footnotetext{
${ }^{1}$ Their data driven procedure rests on the assumption that at one point in the sample the depreciation rate, $\delta_{t}$, remains constant for two periods, i.e. $\delta_{t+1}=\delta_{t}$. This assumption allows them to derive an estimate for the implied capital stock. Through a series of identities they are then able to obtain an estimate for the depreciation rate.

${ }^{2}$ In a similar setup with independent shocks, Bernanke, Gertler, and Gilchrist (1999) and Carlstrom and Fuerst (2001) consider the influence of adjustment and agency costs by allowing for time variation in the cost of capital investment in terms of foregone consumption.
} 
experiment with conditional means for annual depreciation that are all strictly lower than 10 percent and consider various degrees of persistence in the Markov process.

\section{Model Structure and Calibration}

The model is a standard DSGE model with indivisible labor and no artificial frictions aside from a shopping-time motive for holding money. ${ }^{3}$ The model economy is populated by a large number of infinitely lived agents whose expected utility is defined by

$$
E_{0} \sum_{t=0}^{\infty} \beta^{t}\left(\ln \left(c_{t}\right)+\theta \ln \left(1-h_{t}\right)+\theta \frac{L_{t}}{\hat{L}}\left[\ln \left(1-\hat{L}-h_{t}\right)-\ln \left(1-h_{t}\right)\right]\right)
$$

where $\beta$ is the time discount factor; $c_{t}$ is private consumption; $\theta$ is a positive scalar that determines the relative disutility of non-leisure activities; $h_{t}$ is shopping time, $L_{t}$ is expected work time under a Rogerson (1988) employment lottery; $\hat{L}$ is the indivisible time spent at work for those working [Hansen (1985)]. ${ }^{4}$

Aggregate output, $Y_{t}$, is assumed to depend on the total amount of capital, $K_{t}$, and on total hours of work, $N_{t}$, with labor-augmenting technological progress at the gross rate $\lambda$

$$
Y_{t}=e^{z_{t}} K_{t}^{\alpha}\left(\lambda^{t} N_{t}\right)^{1-\alpha}
$$

The shopping-time motive for holding money is really not distinct from a cash-in-

\footnotetext{
${ }^{3}$ Money is in the model for the sake of future extensions. Without monetary policy shocks, money has no material effect on this economy.

${ }^{4}$ We follow the general practice, where lower case letters are used to denote individual choices and upper case letters denote economy-wide per-capita quantities.
} 
advance constraint. Many cash-in-advance models have a cash good and a credit good. If one assumes that buyers have imperfect advance knowledge of which sellers require cash and which offer credit, then holding more money results in less time lost from mistaking a cash-only seller for a credit-offering seller. The shopping time technology specifies the amount of time that must be spent shopping within period $t$ as a function of consumption $c_{t}$ relative to the amount of real money balances, $m_{t}$. The shopping time technology follows the specification given in King and Wolman (1996):

$$
h_{t}=\kappa \frac{m_{t}}{P_{t} c_{t}}+\xi^{1 / \nu}\left(\frac{\nu}{1-\nu}\right)\left(\frac{m_{t}}{P_{t} c_{t}}\right)^{\frac{\nu-1}{\nu}}
$$

where $\kappa$ defines the finite satiation level of real cash balances, $m=\xi c \kappa^{-\nu}$ when the nominal interest rate is zero. A time constraint restricts leisure, shopping time, and work to sum to one:

$$
l_{t}+h_{t}+n_{t}=1
$$

The technology shock, $z_{t}$, is assumed to follow an $\operatorname{AR}(1)$ process with the following law of motion:

$$
z_{t}=\rho z_{t-1}+\epsilon_{t}, \epsilon_{t} \sim N\left(0, \sigma_{\epsilon}^{2}\right)
$$

The technology shock, $\epsilon_{t}$, is drawn from a normal distribution with mean zero and standard deviation $\sigma_{\epsilon}$.

The capital stock evolves according to

$$
k_{t+1}=\left(1-\delta_{S_{t}}\right) k_{t}+i_{t}
$$


where $i_{t}$ is the chosen level of investment and $\delta_{S_{t}}$ is the rate of depreciation of capital, which is assumed to follow a two-state Markov process that is independent of $z_{t} .{ }^{5}$ The installation of capital takes one period, making the time $t+1$ capital stock predetermined at time $t$, but there are otherwise no installation or adjustment costs.

The aggregate resource constraint of the economy is given by

$$
y_{t}=c_{t}+i_{t}
$$

We close the model with an interest rate rule for monetary policy that is a function of lagged inflation and an inflation target:

$$
\Delta r_{t+1}=1.2\left[\pi_{t}-\pi^{*}\right]
$$

Here $\pi$ is inflation and $\pi^{*}$ is the inflation target. Deviations from the inflation target are corrected with a feedback component set to 1.2.

\section{Calibration for the Baseline Model}

The model is calibrated to the parameter values listed in Table 1 . The rate of time preference and the Cobb-Douglas production function coefficients are standard. The values for indivisible labor are taken from Li (1999). The parameters in the shopping-time technology $(\nu=0.75$ and $\zeta=0.04875)$ are from King and Wolman (1996). The autoregressive coefficient for the technology process, $z$, is set to 0.95 . The standard deviation of the technology shocks is set at $\sigma_{\rho}=0.0045$ to match the variance of output in the data when depreciation

\footnotetext{
${ }^{5}$ Without imposing a positive correlation between technology and the depreciation rate, this model does not significantly reduce the probability of technical regress, as time-varying capital utilization can, according to Burnside, Eichenbaum, and Rebelo (1996) and King and Rebelo (2000).
} 
switches as follows. In the extreme case, the depreciation rate switches between 0.015 in the low state and 0.025 in the high state. These values imply an annual depreciation rate between 6 and 10 percent. The low state value is consistent with Stokey and Rebelo (1995) and the high state value with King and Rebelo (2000). Much of our analysis works with a quarterly depreciation rate set to 0.21 , which is consistent with values used by Gilchrist and Williams (2000). The persistence for the two states is defined by

$$
\begin{gathered}
p_{\delta}=P\left(\delta_{t}=\delta_{l o} \mid \delta_{t-1}=\delta_{l o}\right)=0.90 \\
q_{\delta}=P\left(\delta_{t}=\delta_{h i} \mid \delta_{t-1}=\delta_{h i}\right)=0.85
\end{gathered}
$$

\section{Numerical Implementation}

Two features of the dynamic general equilibrium described above make use of traditional solution techniques problematic. Since Markov switching is present in the model's parameters, there is no model steady state to serve as a center of approximation. Even in the absence of shocks to technology or monetary policy, switches in other model parameters will prevent the economy from approaching a steady state value. In addition, the values of these switching parameters in different states are of crucial importance in determining the decisions of agents. Thus the switching cannot simply be "turned-off" to provide a deterministic steady state. As a secondary problem, in cases where agents do not have full information as to the current value of a Markov switching parameter, that is, cases where the parameter is not directly observable, the agent's decisions have to depend on probabilistic beliefs concerning the current parameter value. This necessitates the intro- 
duction of the agent's beliefs as state variables in the agent's optimization problem, and these beliefs have very nonlinear transitions through time.

In light of these problems, we use a solution technique first discussed by Judd (1998), called the projection method. The idea is to approximate the agent's decision rules by polynomials that "nearly" solve the agent's optimization problem in a way made formal below. Using polynomials allows us to represent the approximate rules in a very compact form. While the number of coefficients in a high-degree polynomial in many variables can be somewhat large, this number is nowhere near the number of values that must be kept track when using grid-based methods. For example, a second-degree polynomial in three variables requires 10 coefficients for its specification. A grid-based approximation to a function in three variables using five grid points in each dimension would require specifying $5^{3}$ or 125 parameters. Grid-based approximations to a function of a slightly larger number of state variables - say eight state variables - are impossible for even sparse grids.

To apply the projection method, we express the agent's optimization problem in the following form:

$$
\operatorname{Max}_{u_{t}} E_{0}\left[\sum_{t=0}^{\infty} \beta^{t} r\left(x_{t}, u_{t}, D_{t}\right)\right]
$$

subject to the constraints

$$
x_{t+1}=g\left(x_{t}, u_{t}, D_{t}, \varepsilon_{t+1}\right)
$$

with $x_{0}$ a given. In this formulation, $x_{t}$ is an $n \times 1$ vector of state variables, known by the 
agent at time $t$; $u_{t}$ is an $m \times 1$ vector of the agent's decision variables. The $d \times 1$ vector $D_{t}$ is a vector of variables referred to as economy-wide variables. These are variables that the agent assumes are unaffected by his decisions and which lack fixed transition equations. They will be determined by a set of equilibrium conditions. Finally, $\varepsilon_{t+1}$ is an $e \times 1$ vector of random shocks.

State variables can be further sub-divided into two groups. One group consists of variables that are purely exogenous to the agent. Their transitions will depend only on factors outside of the agent's control, namely themselves and economy-wide variables. These variables represent things like the technology level and the stance of monetary policy. State variables that are under the control of the agent do not have transitions dependent on their current values. For such a variable, $x_{t}^{i}$, controlled by the agent, $x_{t+1}^{i}$ depends only on $u_{t}$, $D_{t}$, and possibly $\varepsilon_{t+1}$. These variables are things specific to the agent such as his savings and money holdings. Our assumption as to transitions for these variables are not really restrictive in that we have yet to come across a dynamic general equilibrium model that cannot be put in a form that satisfies this assumption. The primary reason for this restriction is to enable us to write the agent's first order conditions as described below without having to deal with a value function as well.

In what follows, we denote differentiation with respect to a decision variable with a Greek subscript, $\psi$. Differentiation with respect to a state variable is denoted with a Roman subscript. The first-order conditions of the agent's optimization problem then are: 


$$
r_{\psi}\left(x_{t}, u_{t}, D_{t}\right)+\beta E_{t}\left[\sum_{i \in C} r_{i}\left(x_{t+1}, u_{t+1}, D_{t+1}\right) g_{\psi}^{i}\left(x_{t}, u_{t}, D_{t}, \varepsilon_{t+1}\right) \mid x_{t}\right]=0
$$

for $\psi=1, \ldots, m$. The sum of products of derivatives of the return function and the transitions functions is taken over those variables that are under the agent's direct control, hence the shorthand notation, $i \in C$. The equilibrium can be characterized as a set of functions, $u_{t} \equiv u\left(x_{t}\right)$ and $D_{t} \equiv D\left(x_{t}\right)$, that determine the agent's decisions and the values of the economy-wide variables as functions of today's states. The agent's first-order conditions are $m$ functional equations in these unknown functions. To complete the determination of these unknown functions, we need $d$ more functional equations. These will be equilibrium conditions for the economy and can take a wide range of forms. The usual case is for them to take a simple form such as $e\left(x_{t}, u\left(x_{t}\right), D\left(x_{t}\right)\right) \equiv 0$.

In the concrete case we discuss above, we can express the vectors above as follows:

$$
x_{t}=\left(z_{t}, b_{p, t}, b_{z, t}, \ln \left(R_{t}\right), \ln \left(P_{t-1}\right), \mu_{t-1}, \delta_{t}, k_{t}\right)
$$

where $\mu_{t}$ is the money growth rate, defined as $M_{t} / M_{t-1}$. Note that agent takes the level of technology, beliefs about the current state of the Markov switching parameters, prices, nominal interest rate, and money growth rate as given. The decision vector is:

$$
u_{t}=\left(k_{t+1}, m_{t+1}, l_{t}\right)
$$

where $m_{t+1}$ represents per capita money balances. Finally, the only other variable needed to determine the agent's decisions at time $t$ is the money growth rate needed for the central 
bank to hit its interest rate target; thus $D_{t}$ is simply $\mu_{t}$ and $r\left(x_{t}, u_{t}, D_{t}\right)$ is the agent's utility $U\left(c_{t}, l_{t}\right)$. The three decision variables imply theree first-order conditions. Since percapita money balances $m_{t+1}$ must equal 1 in equilibrium, these three functional equations implicitly determine $k_{t+1}, l_{t}$, and $\mu_{t}$.

Since it is impossible to derive an analytic expression for these unknown functions, they are approximated with polynomials of the following form:

$$
u\left(x_{t}\right) \approx \sum_{d_{1}+d_{2}+\cdots+d_{n} \leq D} c_{\left(d_{1}, d_{2}, \ldots, d_{n}\right)} \varphi_{\left(d_{1}, d_{2}, \ldots, d_{n}\right)}\left(x_{t}\right)
$$

where $D$ is the upper bound on the degree of the polynomial. The $\varphi$ functions are polynomials that take the form:

$$
\varphi_{\left(d_{1}, d_{2}, \ldots, d_{n}\right)}\left(x_{t}\right)=T^{d_{1}}\left(x_{t}^{1}\right) T^{d_{2}}\left(x_{t}^{2}\right) \cdots T^{d_{n}}\left(x_{t}^{n}\right)
$$

where $T^{d_{i}}(x)$ is a polynomial in $x$ with degree $d_{i}$. $T^{d_{i}}(x)$ could, technically, be simply $x^{d_{i}}$, but these polynomials are notorious for their extremely poor approximation properties. Consequently, we use suitably scaled and translated Tchebychev polynomials for the $T^{d_{i}}(x)$ functions. These not only have excellent approximation properties, but are also easy to evaluate with the intrinsic functions that come with most standard software packages. Usually defined on the interval $[-1,1]$ as $T^{n}(x)=\cos (n \arccos (x))$, they can be easily evaluated by any package that has an intrinsic cosine and arccosine function.

In general, $m+d$ functional equations implicitly determine both $u\left(x_{t}\right)$ and $D\left(x_{t}\right)$. Let us denote them as 


$$
R_{\psi}\left(x_{t}, u\left(x_{t}\right), D\left(x_{t}\right)\right)=0
$$

for $\psi=1, \ldots,(m+d)$. We need to find coefficients for the polynomial approximations so that the approximations "nearly" solve the set of functional equations above. There are numerous ways to do this, as described in detail in Judd(1998). The most natural choice is a set of coefficients that sets

$$
\int R_{\alpha}(x, u(x), D(x)) \varphi_{\left(d_{1}, \ldots, d_{n}\right)}(x) d x=0
$$

where these integrals are taken over some pre-determined region of space thought to capture most of the dynamic behavior of the economy and the $\varphi(x)$ functions have been translated to center on this region. This approach is appealing since it transparently gives one equation for each unknown coefficient in each functional approximation. It is also eminently reasonable in that, if for some reason, the equations $R_{\alpha}(x, u(x), D(x))=0$ were satisfied exactly by polynomials $u$ and $D$, these conditions would determine their coefficients exactly. The reader can refer to Judd (1998) for a more detailed discussion of the selection of this particular set of equations and why he calls it a projection method.

As long as the $R_{\alpha}$ functions are set to zero in some average sense over a region, we should have reasonable approximations to the agent's decision rules over this region. Consequently we use a pseudo-random Monte Carlo method to calculate decision rules. Thus, derivation of the coefficients in our polynomial approximations has been reduced to the solution of a set of nonlinear equations in these coefficients. While evaluation of the equations themselves 
can be slow, Broyden's method for solving nonlinear equations works well.

\section{Empirical Results}

An important property of nonlinear decision rules is that higher moments matter. To illustrate this feature of the nonlinear decision rules, we investigate the effect of a meanpreserving spread of the depreciation rate. For this illustration, the low and high quarterly depreciation rates were set to 0.018 and 0.022 . In the first case, the transition probabilities, $p_{\delta}$ and $q_{\delta}$, were both set to 0.9 . A mean-preserving spread sets the two transition probabilities to 0.5 . The variance of the depreciation rate is 2.78 times higher for the case of the mean-preserving spread. Since higher moments matter in the nonlinear decision rules, it is interesting to note what effect risk terms related to depreciation switching have on the level of the output growth path. We simulate the model 400 times with and without the mean-preserving spread and find that the level effect on output lowers output by 0.2 percent (or about 20 billion dollars in the U.S. economy in 2002). Given that the model has time-separable log utility, this level effect is perhaps surprisingly large. One could make it larger through habit persistence if that were a modeling objective. Our main purpose for working with nonlinear decision rules in this article, however, is to investigate the effect of Markov switching depreciation, which implies a nonlinear decision rule, on the comovement of hours and productivity.

We present results on the comovement of hours and productivity in the form of sensitivity analysis and impulse responses. The sensitivity analysis highlights several findings 
surrounding the influence of depreciation on the hours-productivity correlation. In particular, we emphasize that it is the time-varying nature of depreciation, not its level, that is important for generating the hours-productivity correlation. Impulse responses illustrate why the model attains a low correlation between hours and productivity.

\section{Sensitivity Analysis}

We begin our analysis by reviewing the main properties from the case where depreciation is held constant. Figure 1 plots the hours-productivity correlation for constant (quarterly) depreciation rates, $\delta$, between 0.01 and 0.04 . The correlation is 0.86 for $\delta$ ranging between 0.01 and 0.027 . Extreme values of 0.037 or greater are able to generate negative correlations. A depreciation rate of 0.035 is in line with the empirical correlation; such a rate seems unrealistically high, however.

The low hours-productivity correlation arising from high depreciation rates is explained by two features. The first is the increasing use of labor over capital. The second, in terms of economic fluctuations, the variance of hours falls considerably faster than that of output. In other words, the variance of capital increases as depreciation increases. This implies that the fluctuations in productivity must increase, which leads to a lower hours-productivity correlation.

Next, we consider the influence of switching between states with a low and a high depreciation rate. The correlation results are given in Figure 2 for three different processes defined by $\delta+/-\mu$, where $\delta=(0.017,0.02$, and 0.022$)$ and $\mu=(0,0.0005, \ldots, 0.005)$. The transition matrix for the two state process is set to $p_{\delta}=0.9$ and $q=0.85$. The 
results find that relatively small deviations from the conditional mean between $+/-0.003$ and $+/-0.0035$ generate correlations that are consistent with the empirical data. It is important to note that this result stems from the switching and not from high depreciation rates.

As an alternative to the Hodrick-Prescott filter that is applied here and elsewhere in the literature prior to calculating correlations, Cogley (1997) uses a consumption-based measure of the business cycle from Cochrane (1994). With this measure of the cyclical components, Cogley (1997) finds that hours and productivity are negatively correlated. Figure 2 shows that negative correlations easily attained from our model with depreciation switching, with switching, for example, between $\delta=0.017+/-.005$.

We also consider the influence of persistence in the states for $\delta$ on the hours-productivity correlation. Three cases are considered: high-high, low-low and high-low persistence. Highhigh persistence is defined as $p_{\delta}=0.9$ and $q_{\delta}=0.85$ in the transition matrix. High-low persistence takes on the values $p_{\delta}=0.9$ and $q_{\delta}=0.75$ and low-low persistence is defined as $p_{\delta}=0.75$ and $q_{\delta}=0.75$.

The results, summarized in Figure 3 for $\delta=0.02$, find that if the degree of persistence is high in both states, then the depreciation rates do not need to deviate much from each other in order to match the empirical correlations. The opposite result is true when the transition matrix reflects low-low persistence. In this case, considerable switching between the high and low states occurs, but the distance between the mean depreciation rates in the low and high states have to lie further apart in order to obtain the desired hours- 
productivity correlation. The more realistic case of a highly persistent (low mean) state together with a less persistent (high mean) state lies in between the other two cases.

Table 2 presents correlations and standard deviations of our model based data with actual data for the period 1958:1 to 1999:4. The first column gives information of the model with only the technology shock. This model has difficulty matching the investment ratio and the hours-productivity correlation. The introduction of switching in the depreciation rate is unable to resolve the problem with the investment ratio, but offers a substantial improvement for the hours-productivity correlation. It falls from 0.86 to 0.22 .

\section{Impulse Responses}

The precise meaning of impulse responses to a switch in a Markov process requires explanation. In particular, we have to define the 'shock' behind an impulse response. We run parallel simulations of the DSGE model for the 'switch' and 'no switch' scenarios. Both simulations share the same technology shocks and a depreciation rate that randomly follows the Markov switching process until 25 periods before the end of the sample of length $T$. At that point, the first simulated series puts depreciation into the low state for the next six periods; the second series puts depreciation into the low state for the next period, the high state for the next four periods, and then the low state again in the sixth period. A switch in the depreciation rate becomes known in the same period and the endogenous variables reflect this new information, such that the variables should respond in the impulse before the capital stock is affected. After the specified return to the low state in the sixth period, the two series again share a common set of realizations of the Markov switching 
process for depreciation. The four period duration of the high-depreciation state roughly reflects the half life of a spell in that state according to its transition probability, $q_{\delta}=0.85$ $\left(0.85^{4}=0.51\right)$. The difference between the paths of variables with and without the four period sojourn to the high-depreciation state serves as a measure of the impulse response to a switch to the high-depreciation state. The reported impulse response is the average response from 400 simulations of the model.

Figure 4 plots the impulse responses of output, capital, hours and productivity to a switch to the high-depreciation state that lasts four periods. In the low state the depreciation rate $\delta$ is set to 0.018 with transition probability 0.9 , whereas in the high state $\delta=0.022$ with transition probability 0.85 .

The shock to capital generates the typical non-humped shaped dynamics common among RBC models (see Gilchrist and Williams, 2000). More important for us is the observation that depreciation switching tends to push the hours-productivity correlation downward or even make it negative, depending on the degree of switching. With enough variation in the depreciation rate, the negative effect on the hours-productivity correlation can overcome the tendency of technology shocks to induce a positive correlation.

The depreciation shock causes a negative level shift in output. Hours fall initially because the capital stock is relatively high at first in relation to the lower level of output. As the capital stock falls, however, labor hours must be substituted for capital to maintain steady output. When the depreciation rate switches back to the low state, output returns immediately to its initial level. To achieve this level of output, hours must jump above 
their initial level because the capital-output ratio is lower than it was initially. Gradually hours decline as the rebuilding of the capital stock allows for substitution of capital for labor. Throughout this process, the capital-output ratio moves in the opposite direction from hours. Thus, labor productivity moves in the opposite direction from hours. If depreciation switching is of sufficient magnitude and frequency, the negative correlation it imparts between hours and productivity can overcome the positive correlation implied by technology shocks, as shown in Figure 2.

\section{Summary and Conclusions}

In a dynamic stochastic general equilibrium (DSGE) model, we investigate whether a stochastic depreciation rate for capital can account for a low correlation between hours worked and labor productivity when depreciation is only allowed to fluctuate within a narrow range. In the somewhat uninteresting case, as we illustrate, an exceptionally high level of the depreciation rate, rather than its fluctuations, can reduce the hours-productivity correlation. Of greater interest is to is limit the range of fluctuations to plausible rates of depreciation. To do so, we use a two-state Markov process. Such stochastic depreciation switching can capture sudden shifts that occur, for example, when energy-intensive forms of capital are rendered obsolete from an energy shock.

Markov switching in capital depreciation makes the decision rules nonlinear. Our contribution to calculating decision rules for models with Markov switching parameters is to 
apply Judd's (1998) projection method. This approach allows for nonlinear decision rules in a richer set of models with many more state variables than can be solved with grid-based approximations.

Our calibration strategy for the time-varying depreciation rates relies on the empirical work of Abadir and Talmain (2001). They find that depreciation rates for the United States are highly persistent and fluctuate within a narrow band. These properties can be easily incorporated in a Markov-switching process.

With this setup, several results emerge from a simple RBC model augmented with Markov-switching depreciation. The level of depreciation is relatively unimportant for the hours-productivity correlations when depreciation is subject to Markov switching. With relatively small fluctuations in depreciation and switches to the high depreciation state that have a half-life of one year, the model replicates the low 0.24 hours-productivity correlation found in the data, whereas the model without depreciation switching delivers the standard result that the hours-productivity correlation exceeds 0.85 . As the impulse response function shows, a depreciation shock induces a correlation between hours and labor productivity that is about minus one. An appropriate mix of stochastic shocks between technology and depreciation can result in the small positive correlation observed in the data. Such dramatic results suggest that Markov switching is a powerful extension to DSGE models, and the methods we introduce can allow for several Markov switching parameters simultaneously. 


\section{References}

Abadir, Karim and Gabriel Talmain (2001), 'Depreciation Rates and Capital Stocks,' The Manchester School vol. 69(1), 42-51.

Ambler, Steve and Alain Paquet (1994), 'Stochastic Depreciation and the Business Cycle,' International Economic Review vol. 35(1), 101-116.

Bernanke, Ben, Mark Gertler, and Simon Gilchrist (2000), 'The Financial Accelerator in a Quantitative Business Cycle Framework,' in Handbook of Macroeconomics Volume 1C, edited by John Taylor and Michael Woodford (Elsevier).

Andolfatto, David and Paul Gomme (2001), 'Monetary Policy Regimes and Beliefs,' International Economic Review, forthcoming.

Burnside, A. Craig, Martin S. Eichenbaum and Sergio T. Rebelo (1996), 'Sectoral Solow Residuals', European Economic Review vol. 40, 861-869.

Carlstrom, Charles T. and Timothy S. Fuerst (2001), 'Monetary Shocks, Agency Costs and Business Cycles,' Carnegie-Rochester Conference Series on Public Policy vol. 54, 1-27.

Cochrane, John (1994), 'Permanent and Transitory Components of GNP and Stock Prices.' Quarterly Journal of Economics 109, 241-65.

Cogley, Timothy (1997), 'Evaluating Non-Structural Measures of the Business Cycle,' Federal Reserve Bank of San Francisco Review No. 3, 3-21.

Collard Fabrice and Tryphon Kollintzas (2000), 'Maintenance, Utilization, and Depreciation along the Business Cycle' CEPR Working Paper No. 2477.

Greenwood, Jeremy, Zvi Hercowitz, Gregory Huffman, (1988), 'Investment, Capacity Utilization, and the Real Business Cycle,' American Economic Review vol. 78(3), 402-17.

Gilchrist, Simon and John C. Williams (2000), 'Putty-Clay and Investment: A Business Cycle Analysis,' Journal of Political Economy vol. 108, 928-959.

Gong, Fangxiong (1995), 'Regime-Switching Monetary Policy and Real Business Cycle Fluctuations,'Federal Reserve Bank of New York Research Paper: 9528.

Hansen, Gary D. (1985), 'Indivisible Labor and the Business Cycle,' Journal of Monetary Economics vol. 16, 309-327.

Judd, Kenneth L. (1998), Numerical Methods in Economics, Cambridge, Massachusetts: The MIT Press.

Li, Victor E. (1999), 'Can Market-Clearing Models Explain U.S. Labor Market Fluctuations?,' Federal Reserve Bank of St. Louis Review, July/August, 35-49.

Licandro, Omar and Luis A. Puch (2000), 'Capital Utilization, Maintenance Costs and the Business Cycle,' Annales d'Economie et de Statistique vol. 58, 144-164.

King, Robert G. and Sergio T. Rebelo (2000), 'Resuscitating Real Business Cycles,' in Handbook of Macroeconomics Volume 1C, edited by John Taylor and Michael Woodford (Elsevier).

King, Robert G. and Alexander L. Wolman (1996), ' Inflation Targeting in a St. Louis Model of the 21st Century,' Federal Reserve Bank of St. Louis Review vol. 78(3), 83-107.

McGrattan, Ellen R. and James A. Schmitz, Jr. (1999), 'Maintenance and Repair: Too Big to Ignore,' Federal Reserve Bank of Minneapolis Quarterly Review Fall, 2-13.

Rogerson, Richard (1988), 'Indivisible Labor, Lotteries and Equilibrium,' Journal of Monetary Economics vol. 21, 3-16.

Stokey, Nancy and Sergio Rebelo (1996), 'Growth Effects of Flat-Rate Taxes,' Journal of Political Economy vol. 103, 519-550. 
Figure 1: Hours-Productivity Correlation with Constant Depreciation Rates

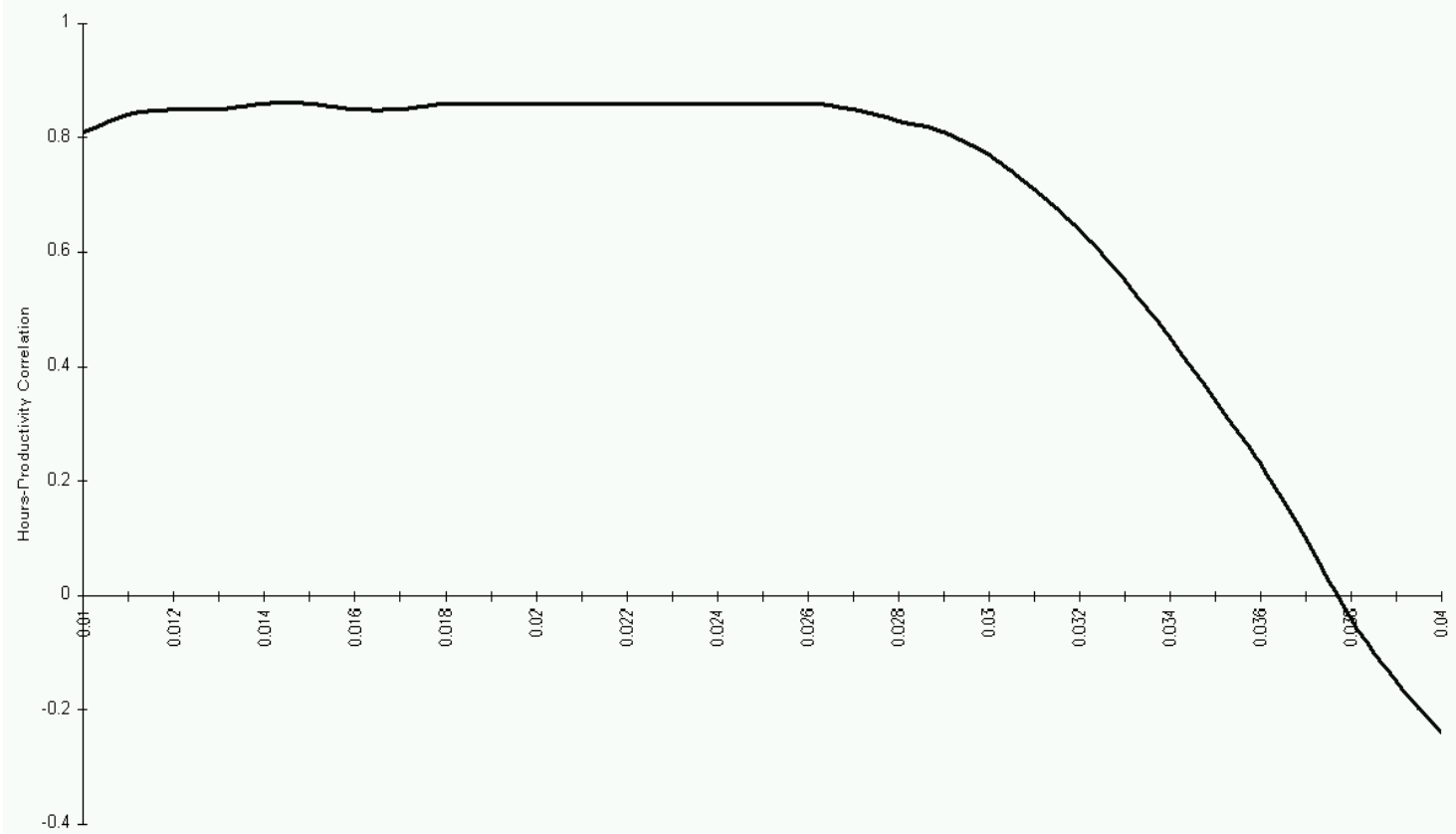

Depreciation Rates 
Figure 2: Hours-Productivity Correlation and the Conditional Mean

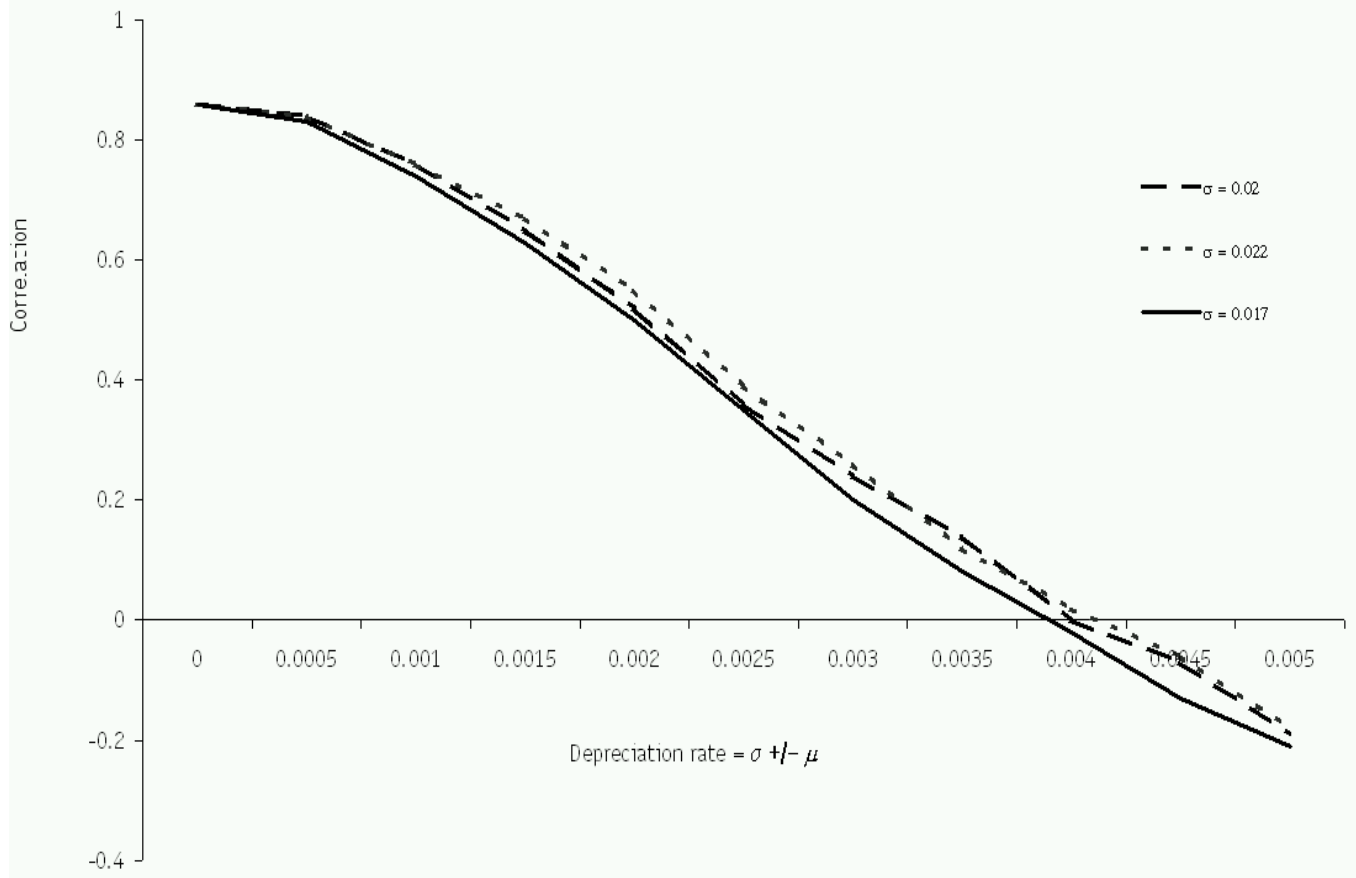




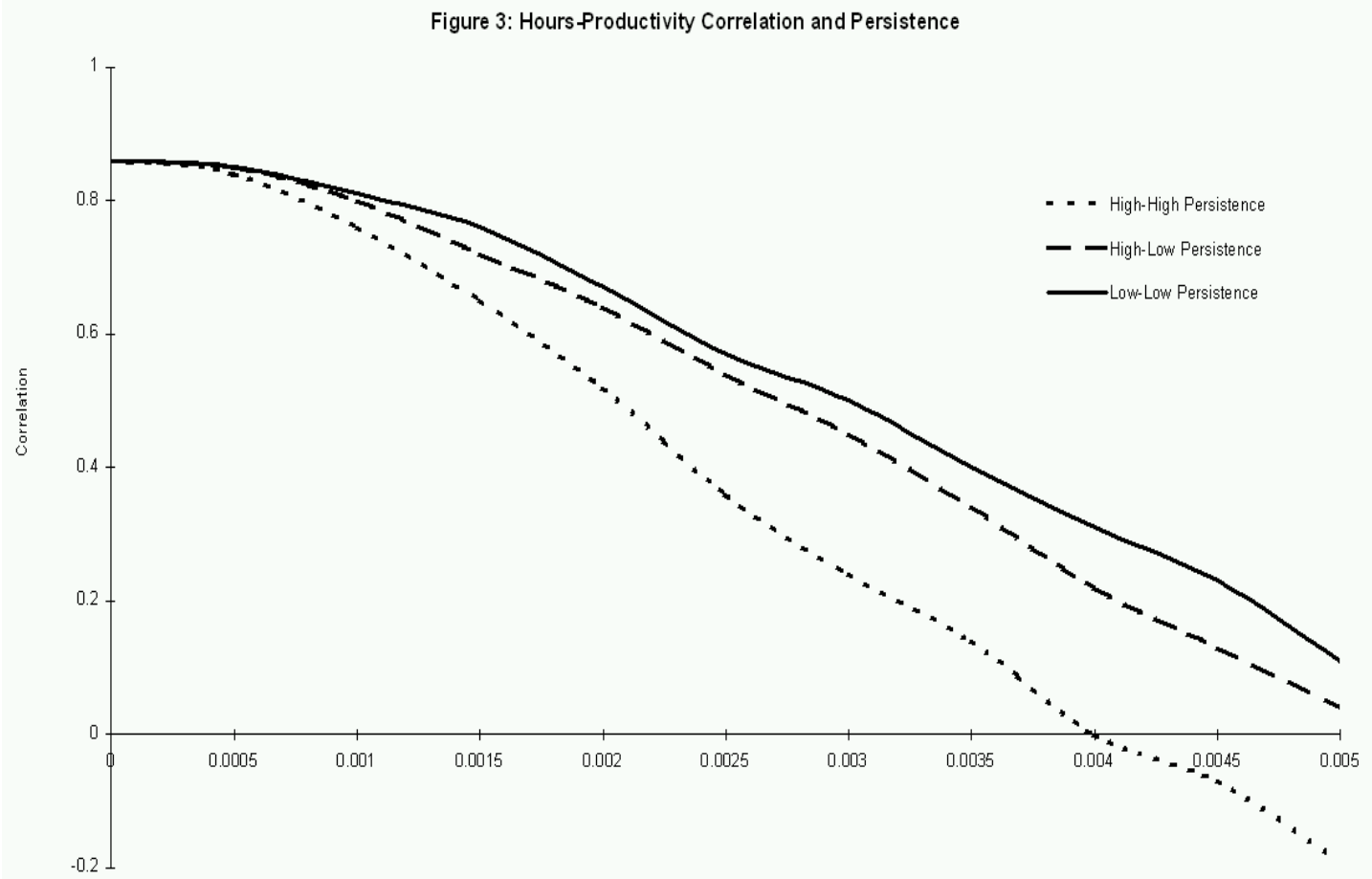

Depreciation rate $=0.02+-\mu$ 
Figure 4: Impulse responses to a switch to the high-depreciation state that lasts four periods

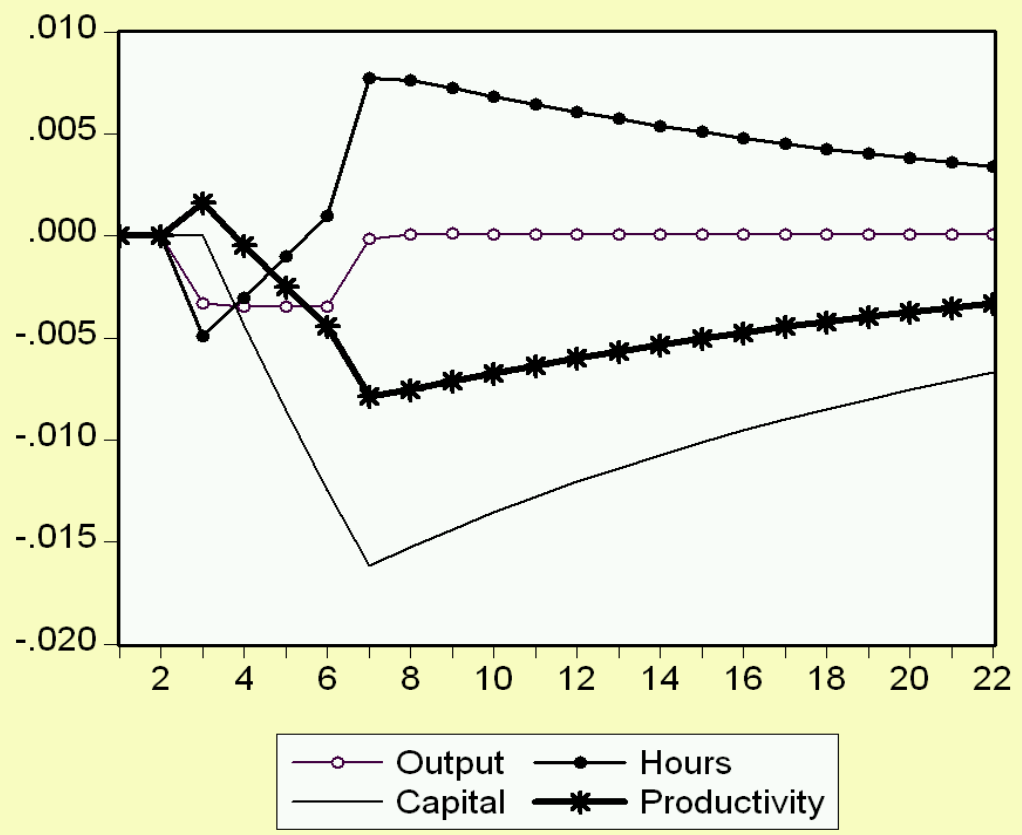




\section{Table 1: Calibration of Markov Switching Economy}

$\begin{array}{ccc}\text { Rate of time preference } & \beta & 0.9917 \\ \text { Production function coefficient } & \alpha & 0.33 \\ \text { Leisure coefficient } & \theta & 2.9474 \\ \text { Labor productivity growth } & \lambda & 1.00373 \\ \text { Indivisible labor } & \hat{L} & 0.25 \\ \text { Shopping time tech. } & \nu & 0.75 \\ \text { Shopping time tech. } & \zeta & 0.04875 \\ \text { Depreciation rates } & \delta & 0.015,0.025 \\ \text { Depreciation transition probability } & p_{\delta}, q_{\delta} & 0.900 .85 \\ \text { AR technology } & & 0.95 \\ & & \end{array}$




\section{Table 2: Business Cycle Statistics for the Switching Model}

\begin{tabular}{cccc} 
& Tech. shock only & with Time-Varying Dep. & Actual Data \\
$\sigma_{y}$ & 1.07 & 1.08 & 1.24 \\
$\sigma_{c} / \sigma_{y}$ & 0.36 & 0.45 & 0.52 \\
$\sigma_{i} / \sigma_{y}$ & 3.10 & 3.37 & 2.50 \\
$\sigma_{n} / \sigma_{y}$ & 0.69 & 0.79 & 0.77 \\
$\sigma_{y / n} / \sigma_{y}$ & 0.35 & 0.46 & 0.46 \\
$\sigma_{n} / \sigma_{y / n}$ & 2.00 & 1.72 & 1.64 \\
$\operatorname{corr}(c, y)$ & 0.94 & 0.68 & 0.84 \\
$\operatorname{corr}(i, y)$ & 0.94 & 0.95 & 0.92 \\
$\operatorname{corr}(n, y)$ & 0.99 & 0.89 & 0.88 \\
$\operatorname{corr}(y / n, y)$ & 0.94 & 0.63 & 0.66 \\
$\operatorname{corr}(y / n, n)$ & 0.86 & 0.22 & 0.25 \\
\hline
\end{tabular}

